\title{
EI despido de los trabajadores por la automatización de sus puestos de trabajo: ¿es posible?
}

The dismissal of workers due to the automation of their workplaces: is it possible?

\author{
DJAMIL TONY KAHALE CARRILLO \\ Profesor Titular de Derecho del Trabajo y de la Seguridad Social. \\ Universidad Politécnica de Cartagena (España)
}

djamil.kahale@upct.es

https://orcid.org/0000-0002-0266-3380

\begin{abstract}
Resumen: La Industria 4.0, conocida como la cuarta revolución industrial, se está implementando en España. Lo que supone que los empresarios están apostando por su establecimiento, a través de las tecnologías que las involucra, tales como cloud, Big Data, sistemas ciber-físicos, sensórica, robótica colaborativa, fabricación aditiva o por capas, entre otras. Se puede inferir, por tanto, que la llegada de aquellas tecnologías en el trabajo puede que genere, entre otras cosas, despidos en las empresas que la implementan. El presente estudio tiene por objeto analizar si se considera legal despedir a un trabajador por la automatización de su puesto de trabajo.
\end{abstract}

Abstract: Industry 4.0, known as the fourth industrial revolution, is being implemented in Spain. This means that businessmen are betting on its establishment, through the technologies involved, such as cloud, Big Data, cyber-physical systems, sensoring, collaborative robotics, additive or layered manufacturing, among others. It can be inferred, therefore, that the arrival of those technologies at work may generate, among other things, layoffs in the companies that implement them. The purpose of this study is to analyze whether it is legal to dismiss a worker because of the automation of his or her job.

Palabras clave: despido, digitalización, automatización, industria 4.0, trabajadores, robots.

Keywords: redundancy, digitization, automation, industry 4.0, workers, robots. 
Sumario: 1. INTRODUCCIÓN. 2. EL DESPIDO OBJETIVO. 3. LA CARTA DE DESPIDO. 4. LA INTELIGENCIA ARTIFICIAL EN EL PUESTO DE TRABAJO. 5. LA LIBERTAD DE EMPRESA Y EL DERECHO DEL TRABAJO. 6. CONCLUSIONES. 7. BIBLIOGRAFÍA.

\section{INTRODUCCIÓN}

La Industria 4.0 consiste en incorporar las nuevas tecnologías a la industria ${ }^{1}$. Dicho en otros términos, es hacer andar la industria a través de herramientas tecnológicas, tales como cloud, Big Data, sistemas ciber-físicos, sensórica, robótica colaborativa, fabricación aditiva o por capas, entre otras. Por tanto, es la considerada como la cuarta revolución industrial.

El informe Industria conectada 4.0: La transformación digital de la industria española, del Ministerio de Industria, Energía y Turismo, define Industria 4.0 como "la cuarta revolución industrial, que se basa en la disponibilidad en tiempo real de toda la información relevante al producto, proporcionada por una red accesible en toda la cadena de valor, así como la capacidad para modificar el flujo de valor óptimo en cualquier momento. Esto se logra a través de la digitalización y la unión de todas las unidades productivas de una economía. Para ello es necesaria la fusión de tecnologías tales como Internet de las Cosas (IoT), computación y cloud, big data y ciberseguridad, así como las complementarias: móvil, analytics, M2M (Machine to Machine), impresión 3D, robótica y comunidad/compartición”2.

La digitalización es la herramienta que diferencia a la Industria 4.0 con las demás, dado que combina el aspecto físico con el digital. Como, por ejemplo, la vinculación de materiales, dispositivos, instalaciones, maquinarias al sistema digital. Se han dado voces al señalar que la digitalización une el puente que combina en el extremo a sociedad y tecnología que conecta con el otro extremo del mundo físico con el virtual ${ }^{3}$.

En las nuevas fases del cambio no se trata de vender lo que las industrias venden, sino de producir lo que los clientes piden y necesiten. Por tanto, la Industria 4.0 va a transformar la

\footnotetext{
${ }^{1}$ Esta obra queda enmarcada dentro de los trabajos de investigación desarrollados por el autor en el Proyecto financiado por la Comunidad Autónoma de la Región de Murcia a través de la convocatoria de Ayudas a proyectos para el desarrollo de investigación científica y técnica por grupos competitivos, incluida en el Programa Regional de Fomento de la Investigación Científica y Técnica (Plan de Actuación 2018) de la Fundación Séneca-Agencia de Ciencia y Tecnología de la Región de Murcia: 20976/PI/18: El impacto de la Industria 4.0 en el trabajo: Una visión interdisciplinar.
}

${ }^{2}$ MINISTERIO DE INDUSTRIA, ENERGÍA Y TURISMO, Industria conectada 4.0: La transformación digital de la industria Española, Ministerio de Industria, Energía y Turismo, Madrid, 2015, pág. 26. El informe en cuanto al término industria que utiliza hace referencia a la "industria manufacturera, excluyendo el suministro de energía y agua y las industrias extractivas".

${ }^{3}$ CCOO INDUSTRIA, La digitalización de la industria, CCOO, Madrid, 2015, pág. 8. 
naturaleza de los mercados, la forma de acceder a aquellos y acrecentará la intensidad de capital, por lo que requerirá que se aumenten las habilidades y conocimientos de los empleados ${ }^{4}$.

El informe del Foro Económico Mundial de Davos de 2016, concluye que la digitalización de la industria supondrá la desaparición de 7,1 millones de empleos en los 15 países más industrializados del mundo; y la creación de 2,1 millones de nuevas posiciones para 2020; la mayoría relacionados con las nuevas capacidades y habilidades digitales (ingenieros, informáticos y matemáticos, principalmente $)^{5}$.

Los informes señalan que más del $40 \%$ de los empleos se automatizaran en el futuro. Por una parte, el informe McKinsey Quarterly indica que el 45\% de las actividades de trabajo podrían automatizarse utilizando la tecnología en los Estados Unidos de América. Empero, si las tecnologías que procesan y entienden el lenguaje natural y alcanzaran el nivel medio de desempeño humano, se podría automatizar un $13 \%$ adicional de las actividades de trabajo ${ }^{6}$.

Por otra, el estudio The Future of Employment: How susceptible are jobs to computerisation?, de la Universidad de Oxford, vaticina que para 2020 de 702 actividades profesionales estudiadas de aquel país serán automatizadas un $47 \%$. No obstante, hay que distinguir que tareas y puestos de trabajo no tienen el mismo significado. Estos últimos engloba múltiples tareas, como la interacción física o la interacción social ${ }^{7}$.

Este último informe evalúa el impacto sobre el empleo, para determinar cuáles de las tareas de cada profesión o puesto de trabajo pueden ser automatizadas. De igual manera, señala tres grupos de tareas que la tecnología no es capaz, de momento, de perfeccionar o materializar: a) Inteligencia emocional (persuadir a alguien), b) Inteligencia creativa (hacer una broma), c) Percepción y manipulación en entornos desordenados. Las tareas más susceptibles de automatización son las de servicios, producción, transporte, ventas, trabajos administrativos, entre otras.

Uno de los principales desafíos que se tiene es que a pesar de que la industria española utiliza las nuevas tecnologías, no se tiene el personal capacitado para que las puedan manejar. Dicho en otras palabras, se requiere de una mano de obra más cualificada que abandone el trabajo manual por el software ${ }^{8}$, con funciones de simulación productiva y control de la eficiencia. Por

\footnotetext{
${ }^{4}$ TORNABELL CARRIO, R., “Industria 4.0: ¿Qué impacto tiene en la producción y el empleo?”, La Revista del Foment, núm. 2146, 2016, pág. 41.

${ }^{5}$ WORLD ECONOMIC FORUM, The Future of Jobs Employment, Skills and Workforce Strategy for the Fourth Industrial Revolution, World Economic Forum, Ginebra, 2016.

${ }^{6}$ MCKINSEY \& COMPANY, Four fundamentals of workplace automation, McKinsey Quarterly, noviembre de 2015.

7 MORRON SALMERON, A., ¿Llegará la Cuarta Revolución Industrial a España?, CaixaBank Research, febrero, 2016.

${ }^{8}$ La Real Academia define software como el conjunto de programas, instrucciones y reglas informáticas para ejecutar ciertas tareas en una computadora. www.rae.es
} 
ello, se afirma que "las nuevas tecnologías están provocando en la actualidad una alteración del mercado de trabajo pero una reacción ludita no lo evitará"9.

$\mathrm{El}$ informe de $\mathrm{CCOO}$ "Industria 4.0: una apuesta colectiva" señala que un $75 \%$ de los oficios y las profesiones futuras no existen, de momento, por lo que estarán relacionadas con los sistemas informáticos, la gestión de datos, la seguridad informática, los sistemas robóticos, entre otros. Por ejemplo, pilotos de drones, telecirujanos, coordinadores de la relación hombre-máquina en el ámbito laboral, arquitectos de realidad aumentada, etc. ${ }^{10}$

Asimismo, el informe de CCOO "La Digitalización y la Industria 4.0: Impacto industrial y laboral" "11 indica los resultados de ciertos trabajos que realizan previsiones sobre el impacto en el mercado de trabajo que apuntan a una falta de profesionales. Para una mejor comprensión, en las siguientes tablas se pueden observar el impacto de la implantación de la cuarta revolución industrial en el mercado de trabajo.

\section{Profesiones y riesgos de automatización}

Profesión

Médicos de familia

Compositores, músicos y contantes

Economistas

Artistas financieros

Transportistas (coches, taxis,

furgonetas)

Empleados de contabilidad
Grupo de riesgo

Bajo

Bajo

Medio

Medio

$46 \%$

Medio

$56,78 \%$
Alto

$97 \%$

\footnotetext{
${ }^{9}$ MERCADER UGUINA, J., El futuro del trabajo en la era de la digitalización y la robótica, Tirant lo Blanch, Valencia, 2017, pág. 244.

${ }^{10}$ CCOO INDUSTRIA, Industria 4.0. Una apuesta colectiva, CCOO, Madrid, 2015, pág. 29.

${ }^{11}$ CCOO INDUSTRIA, La Digitalización y la Industria 4.0: Impacto industrial y laboral, CCOO, Madrid, 2017.
} 
Fuente: CCOO INDUSTRIA, La Digitalización y la Industria 4.0: Impacto industrial y laboral, CCOO, Madrid, 2017, pág. 41.

\section{Empleos con mayor riesgo de Empleos con menor riesgo automatización/digitalizació de \\ n automatización/digitalizaci Nuevos empleos ón}

Trabajo de oficina y tareas administrativas

Educación, Arte y medios de comunicación

Servicios jurídicos

Desarrolladores de software y aplicaciones

Transporte, logística

Gestión, gestión de recursos humanos

Especialistas en redes, inteligencia artificial, etc.

Negocio

Industria manufacturera

Algunos aspectos de los servicios financieros
Diseñadores y productores de nuevas máquinas inteligentes, robots e impresoras 3D

Construcción

Proveedores de servicios de salud

Especialistas en marketing digital y comercio electrónico

\footnotetext{
Algunos aspectos de los Trabajadores informáticos, La parte baja de la escala servicios financieros ingenieros y científicos

Los esclavos de las galeras, galeotes digitales (trabajadores de la entrada de datos o del filtro) y otros "mecánicos turcos" que
} 
trabajan en las plataformas

digitales

$\begin{array}{lll}\text { Algunos tipos de servicios Algunos tipos de servicios Los conductores de Uber, } \\ \text { (traducción, consultoría fiscal, (trabajo social, peluquería, los empleos causales o } \\ \text { cuidado de belleza, etc.) } & \begin{array}{l}\text { "raros" (reparaciones, } \\ \text { etc.) }\end{array} \\ & \begin{array}{l}\text { mejoras del hogar, cuidado } \\ \text { etc.) en la economía }\end{array} \\ & \text { colaborativa }\end{array}$

Fuente: CCOO INDUSTRIA, La Digitalización y la Industria 4.0: Impacto industrial y laboral, CCOO, Madrid, 2017, pág. 50.

Bajo este contexto, se puede inferir que la llegada de aquellas tecnologías ${ }^{13}$ en el trabajo puede que generen despidos en las empresas que la implementan. El presente estudio tiene por objeto analizar si se considera legal despedir a un trabajador por la digitalización de su puesto de trabajo a través de la automatización de su puesto de trabajo. Para ello se llevará a cabo, entre otras cosas, el análisis de la sentencia 23 de septiembre de 2019, del Juzgado de lo Social núm. 10 de Las Palmas de Gran Canaria, núm. 479/2019; bajo los siguientes epígrafes: el despido objetivo, la carta de despido, la inteligencia artificial en el puesto de trabajo, la libertad de empresa y el Derecho del Trabajo.

\section{EL DESPIDO OBJETIVO}

El artículo 52 del Real Decreto Legislativo 2/2015, de 23 de octubre, por el que se aprueba el texto refundido de la Ley del Estatuto de los Trabajadores $(\mathrm{ET})^{14}$, está diseñado para que el empresario pueda despedir al trabajador cuando existen causas objetivas, tasadas por la norma, que dificultan que aquel siga prestando servicios en la empresa (por ejemplo, ineptitud del trabajador y falta de adaptación). Asimismo, el apartado c) de aquel precepto dispone que, por las mismas causas económicas, organizativas, tecnológicas o productivas previstas para

\footnotetext{
${ }^{12}$ La Comisión Europea ha señalado que "la economía colaborativa crea nuevas oportunidades de empleo, genera ingresos más allá de las relaciones de empleo lineales tradicionales y hace posible que las personas trabajen con arreglo a modalidades flexibles. Eso les permite ser económicamente activas cuando las formas más tradicionales de empleo no son adecuadas para ellas o no están a su disposición. Al mismo tiempo, las modalidades de trabajo flexible pueden no ser tan regulares o estables como las relaciones de empleo tradicionales". COM (2016) 356 final, Una Agenda Europea para la economía colaborativa.

${ }^{13}$ La Real Academia Española define inteligencia artificial como aquella disciplina científica que se ocupa de crear programas informáticos que ejecutan operaciones comparables a las que realiza la mente humana, como el aprendizaje o el razonamiento lógico. www.rae.es

${ }^{14}$ BOE núm. 255, de 24 de octubre de 2015.
} 
justificar el despido objetivo, aquel sea posible, a su vez, cuando afecte a un número de trabajadores inferior al del despido colectivo.

Hay que destacar que el apartado d) de aquel precepto ha sido derogado por el artículo único de la Ley 1/2020, de 15 de julio, por la que se deroga el despido objetivo por faltas de asistencia al trabajo establecido en el artículo 52.d) del texto refundido de la Ley del Estatuto de los Trabajadores, aprobado por el Real Decreto Legislativo 2/2015, de 23 de octubre ${ }^{15}$. Procedente del Real Decreto-ley 4/2020, de 18 de febrero, por el que se deroga el despido objetivo por faltas de asistencia al trabajo establecido en el artículo 52.d) del texto refundido de la Ley del Estatuto de los Trabajadores, aprobado por el Real Decreto Legislativo 2/2015, de 23 de octubre $^{16}$.

Precepto que ha sido utilizado por una empresa hotelera (art. 52 c) ET) al despedir a una trabajadora por la robotización o automatización de sus funciones administrativas. Situación que ha sido resuelta por la Sentencia del Juzgado de lo Social núm. 10 de Las Palmas de Gran Canaria, de 23 de septiembre de 2019, núm. recurso 470/2019 ${ }^{17}$; resolución pionera que será la base fundamental de este análisis. La trabajadora impugna el despido por considerarlo improcedente, dado que no son ciertos los hechos señalados en la carta de despido. La situación productiva que alega el hotel se funda en previsiones, aún no constatadas al tiempo del despido.

Hay que advertir que las causas de extinción del contrato no vinculadas a los resultados económicos globales de la empresa, para cuya operatividad no se exige; es que la entidad atraviese una situación económica negativa, pueden ser de tres tipos: técnicas, organizativas o de producción. Por consiguiente, son las tres causas alegadas como determinantes del despido objetivo en cuestión.

La definición de causas técnicas, organizativas y productivas viene circundada por los criterios sentados por la jurisprudencia del alto Tribunal sobre el particular ${ }^{18}$ : a) Causas técnicas: según afecte a cambios en la esfera de los medios o instrumentos de producción; b) Causas organizativas: al ámbito de los sistemas y métodos de trabajo del personal o en el modo de organizar la producción; y, c) Causas productivas: al entorno de los productos o servicios que la empresa pretende colocar en el mercado.

Por consiguiente, el ámbito de las causas organizativas o de la producción es el del centro de trabajo en que las mismas concurran, al revés de lo que ocurre con las causas económicas, que han de apreciarse al nivel de la empresa en su conjunto. La valoración de la concurrencia de la

\footnotetext{
15 BOE núm. 194, 16 julio de 2020.

${ }^{16}$ BOE núm. 43, 19 de febrero de 2020.

${ }^{17} \mathrm{http} / / / \mathrm{www} \cdot$ poderjudicial.es/search/openDocument/ba043c7140ea570b

${ }^{18}$ STS 14 de junio de 1996.
} 
causa productiva $u$ organizativa ha de referirse al ámbito en que es necesaria la reorganización y no a la totalidad de la empresa ${ }^{19}$.

Este grupo de causas tienen su origen en los cambios que se producen en sectores limitados de la vida de la empresa, a diferencia de las económicas que se refieren a la rentabilidad de la entidad en su conjunto ${ }^{20}$ y se proyectan en el plano de la competitividad de la empresa, pudiendo aparecer totalmente desvinculadas de la existencia de pérdidas o resultados económicos desfavorables. Para que tales cambios por causas organizativas y productivas puedan operar como causa de extinción colectiva o individual de relaciones laborales será preciso que provoquen una reducción real de las necesidades de mano de obra, de modo que la medida permita mantener o restablecer la equivalencia entre las nuevas exigencias y el personal contratado para atenderlas.

Concurren, por tanto, cuando se producen cambios, entre otros posibles ámbitos de la estructura organizativa de la empresa, en el diseño y funcionamiento de los sistemas y métodos de trabajo del personal o en el modo de organizar la producción, que generan sobrantes de plantilla. Por lo que debe producirse un evento objetivo previo que, a su vez, justifique la nueva medida reorganizativa, que es la que determina finalmente la extinción de los contratos de trabajo ${ }^{21}$.

\section{LA CARTA DE DESPIDO}

La cuestión por dilucidar en el estudio es la declaración ilegítima del despido realizado a una trabajadora por una empresa hotelera, que ha sido sustituida por un software de gestión que es capaz de realizar las mismas tareas. Las causas productivas que afectan al ámbito de los productos o servicios que la empresa hotelera, según señala la sentencia, pretende colocar en el mercado, y estos productos o servicios, que son de gestión de intermediación turística y de administración, explotación y gerencia de sociedad dedicadas a la actividad turística no había cambiado al tiempo del despido. No ha surgido un nuevo producto turístico, ni ha desaparecido ninguno. La empresa hotelera, por ese alegato, pretende hacer valer que el mercado turístico está en declive, que los datos y las expectativas son negativos; empero, lo que hace es adelantarse a un futuro que aún no se ha producido.

La causa productiva podría afectar a que el producto o servicio que ofrece la empresa, estuviera en franca decadencia; sin embargo, no puede basarse aquella en que dicho producto tiene visos de alcanzar la decadencia en un futuro, incierto y sin proximidad definida.

La carta de despido se centra en analizar la situación del mercado turístico; no obstante, incurre en el error de proyectar a futuro sus previsiones negativas, sin que se encuentre al tiempo del

\footnotetext{
${ }^{19}$ SSTS 13 de febrero y 19 de marzo 2002.

${ }^{20}$ STS 21 de julio de 2003.

${ }^{21}$ STS 21 de abril de 2014 y STSJ Madrid 25 de noviembre de 2013.
} 
despido; una circunstancia objetiva y real de empeoramiento del sector, más allá de los datos puntuales. Por tanto, se trata de un índice adelantado; por lo que no constata hechos, sino que presume el futuro. Los indicadores adelantados son indicadores que por lo general cambian antes de que cambie el ciclo económico/productivo, pudiendo ser útiles como predictores a corto plazo de la economía, pero en todo caso, no pueden ser base para una causa productiva de un despido objetivo.

\section{LA INTELIGENCIA ARTIFICIAL EN EL PUESTO DE TRABAJO}

La empresa hotelera alega que se ha procedido a la "robotización de parte de las funciones administrativas que hasta el momento venían siendo desarrolladas directamente por el personal". Desde un punto de vista técnico, la empresa no ha procedido a la robotización, sino a la automatización a través de software. Dicho en otras palabras, no existe robot físico alguno que haya asumido tareas, sino que un software -dotado de reconocimiento óptico de caractereslee determinados documentos, extrae la información y hace con ella aquello para lo que está programado $^{22}$.

Para que sea considerado robot debería de existir "la forma del soporte físico del robot", entre otras, como exige el Parlamento Europeo en el Anexo a la Resolución del Parlamento Europeo, de 16 de febrero de 2017, con recomendaciones destinadas a la Comisión sobre normas de Derecho civil sobre robótica ${ }^{23}$. En definitiva, se trata de un software instalable en cualquier servidor generalista, sin perjuicio de que por razones comerciales se emplee el término robot y no bot, de manera equivocada (comercialmente se vende como "robot de software").

La empresa hotelera ha llevado a cabo la instalación de un RPA, acrónimo de Robotic Process Automation, o Automatización de Procesos mediante la Robótica. En definitiva, es el uso de software en bot para realizar, entre otras, tareas corporativas rutinarias, como el procesamiento de formularios, entrada de datos. Bajo este contexto, aquella señala que la implantación del bot, respondía a la "necesidad de adaptación a los cambios constantes que se vienen dando en el sector". De igual manera, alega la necesidad de modernizar los sistemas en aras de "aumentar la competitividad de la Empresa dentro del mercado y mejorar los resultados en términos de eficiencia y coste, incrementando la eficiencia en la ejecución de operaciones recurrentes en los procesos financieros-administrativos a través de un modelo de operación más competitivo como el que permite los softwares de automatización de procesos mediante robots".

\footnotetext{
${ }^{22}$ La Real Academia Española (RAE) define robot como aquel programa que explora automáticamente la red para encontrar información o la máquina o ingenio electrónico programable que es capaz de manipular objetos y realizar diversas operaciones. www.rae.es

${ }^{23}$ La Resolución, a su vez, añade la capacidad de adquirir autonomía mediante sensores y/o mediante el intercambio de datos con su entorno (interconectividad) y el análisis de dichos datos; la capacidad de aprender a través de la experiencia y la interacción; y, la capacidad de adaptar su comportamiento y acciones al entorno.
} 
La sentencia recalca que son causas técnicas aquellas que afectan a los medios o instrumentos de producción, como a los cambios que en los mismos se produzcan. En el supuesto que se estudia, nace un nuevo elemento a valorar: un software que automatiza lo que antes se realizaba manualmente, prescindiendo de la necesidad del trabajador humano.

Las razones estrictamente económicas, resultan claras de despido al disponer que "los costes asociados a la implantación del RPA (licencia de servidor, nodo de producción y configuración), ascienden a un total de 12.900 euros anuales, en tanto que el coste de mantenimiento del puesto de trabajo de la actora, representa para la Empresa 28.412,44 euros anuales (salario + Seguridad Social). Si además de ello tenemos en cuenta que el 'bot' trabaja de 17:30 a 06:00 horas entre semana (12 horas y media) y 24 horas los fines de semana y festivos, lo que resulta claro es que por 12.900 euros anuales se desempeña un trabajo de 392 horas (98 a la semana), mientras que por $28.412,44$ euros se desempeña un trabajo de 160 horas (40 a la semana). Es decir, que el 'bot' desempeña el trabajo correspondiente a 2,45 trabajadores al mes, lo cual vendría a coincidir con los trabajadores cuyos puestos han sido afectados por la implantación de la RPA, (...). Es decir, que aún cuando el robot hiciera el trabajo en la misma cantidad de tiempo que la actora, la posibilidad de tenerle trabajando más horas, vendría a determinar la posibilidad de sustituir al menos a dos trabajadores".

Resulta indudable que toda automatización suele conllevar una mejora en la eficiencia, pero en el supuesto que se estudia no hay una acreditación específica, con números concretos y detalle explicativo de los mismos. De forma concluyente, no queda acreditada la causa técnica, a la que va ligada la organizativa, por el hecho de que las horas que no quedan vacías de contenido a la trabajadora se repartirían entre los demás trabajadores.

\section{LA LIBERTAD DE EMPRESA Y EL DERECHO DEL TRABAJO}

La sentencia acude a los dos elementos que se enfrentan en un despido objetivo: la libertad de empresa y el Derecho al Trabajo. Empero, por encima de ellos, se encuentra el interés público en el mantenimiento del empleo. Y este interés público nace de una de las características propias de un Estado Social, que reconoce derechos y ofrece una serie de garantías.

En el supuesto que se analiza se está ante un fenómeno que supera lo puramente "técnico", y que supera incluso la "libertad de empresa", alcanzando a la estabilidad del empleo en su conjunto, como es la automatización de labores repetitivas que no ofrecen un valor añadido. Son múltiples los estudios que llevan a cabo un análisis prospectivo sobre los trabajos automatizables en cada economía, y son múltiples las fórmulas empleadas para ello.

La digitalización es capaz de automatizar profesiones cualificadas, como economistas, contables y analistas financieros, entre otros. Empero, aquellas actividades en las que la interacción humana y la creatividad tienen mayor importancia son las que no se automatizaran, como músicos, médicos, maestros, trabajadores sociales, entre otros. El estudio de CaixaBank Research estima que "un $43 \%$ de los puestos de trabajo actualmente existentes en España tienen un riesgo elevado (con una probabilidad superior al 66\%) de poder ser automatizados a medio 
plazo, mientras que el resto de los puestos de trabajo quedan repartidos a partes iguales entre el grupo de riesgo medio (entre el $33 \%$ y el 66\%) y bajo (inferior al 33\%)"24.

El informe BBVA Research, sin embargo, estima que a partir de la información a tres dígitos de la Clasificación Nacional de Ocupaciones (CNO2011) y tras atribuir a cada ocupado de la Encuesta de Población Activa (EPA) la probabilidad de automatización de la ocupación que desempeña, se obtiene que el 36\% del empleo en España se encontraría en riesgo elevado de digitalización. La orientación productiva de España, con un mayor peso de determinados servicios en el empleo, podría estar reduciendo el porcentaje de ocupados vulnerables a la computarización. Entre dichos servicios destacan las labores administrativas especializadas, la recepción en establecimientos hoteleros o los empleados domésticos ${ }^{25}$.

Atendiendo a lo anterior, resulta claro que la automatización de procesos, como la operada en el caso que se analiza, implicará una destrucción de empleos de al menos el 35\% de la población activa, por lo que un elemento de este carácter tiende a la mera optimización de costes. La libertad de empresa se enfrenta así con el interés público por mantener el empleo y, por consiguiente, con el Derecho al Trabajo. Siendo el despido objetivo una forma privilegiada, y si se quiere excepcional, de concluir una relación laboral con una indemnización inferior a la ordinaria. Bajo esta perspectiva, no puede calificarse de excepcional aquella causa que pueda afectar al anterior porcentaje de todos los trabajos.

Por otra parte, según el informe elaborado por $\mathrm{CCOO}$ dispone que durante la crisis económica de 2008 a 2012, se destruyó el 8,2\% de los empleos ${ }^{26}$. Los datos prospectivos de destrucción de empleo por la automatización son muy superiores, y, por ende, hacen necesaria una reinterpretación del concepto de causas técnicas para el despido objetivo.

Bajo esta premisa, hay que destacar que las causas técnicas parten, entre otros, de un cambio en los medios o instrumentos de producción. En el caso de la automatización implica la irrupción de algo nuevo, y no el cambio de algo pasado. Por ejemplo, el cambio de un instrumento de producción, podría ser la transformación de las cámaras fotográficas analógicas

\footnotetext{
24 "No obstante, no hay que confundir el potencial de robotización de la economía con la desaparición de los empleos. La tecnología destruye profesiones, pero no la posibilidad de trabajar. La automatización de las profesiones que conocemos hoy en día ofrece la posibilidad de reorientar la naturaleza del trabajo, liberando a los trabajadores para que puedan dedicarse a nuevas actividades en las que desarrollen todo su potencial, como ya hicieron el aspirador o la lavadora en el ámbito doméstico. La mayoría de los trabajadores dedican gran parte de su tiempo a tareas en las que desaprovechan su ventaja comparativa respecto al robot, por lo que existe un gran potencial para crear nuevas profesiones si las instituciones y los individuos aprovechan la ocasión. Los robots tienen una gran capacidad lógica y de gestión del big data, pero la inspiración, la intuición y la creatividad quedan lejos de su alcance”. MORRON SALMERON, A., ¿Llegará la Cuarta Revolución Industrial a España?, CaixaBank Research, febrero, 2016.
}

${ }^{25}$ DOMÉNECH, R., GARCÍA, J., MONTAÑEZ, M. y NEUT, A., “¿Cuán vulnerable es el empleo en España a la revolución digital?”, BBVA Research, Observatorio Económico, 19 de marzo de 2018, pág. 3.

${ }^{26}$ ROCHA, F., La crisis económica y sus efectos sobre el empleo en España, Gaceta Sindical, CCOO, Madrid. 
a cámaras fotográficas digitales ${ }^{27}$, en la que el trabajo de revelado y tratamiento desaparece y gran parte de la labor de un fotógrafo manual puede desaparecer. Empero, en el supuesto que se analiza, se pasa de que los trabajadores hagan uso de un instrumento de producción para el desempeño de su trabajo, a que el instrumento de producción haga ese trabajo por sí.

Por ello, no se produce un cambio en el medio o instrumento de producción, lo que se origina es la sustitución de un trabajador por un instrumento. Lo contrario sería tanto como considerar al trabajador un instrumento y la aparición de un robot o bot un cambio en ese instrumento.

La sentencia señala que ha de partirse de una visión finalista de la circunstancia, esto es, de los efectos que a futuro ello puede suponer. La introducción de bot en el entorno laboral implica la multiplicación de la productividad, en cuanto uno solo de aquel puede hacer el trabajo de más de un trabajador, y con ello el aumento de la competitividad sobre la base de reducir costes. Empero, esos costes que se reducen, se circunscriben en prescindir totalmente de los trabajadores.

Por tanto, se funda la mejora de la competitividad como elemento único que justifique el despido, mediante la introducción de bot que automaticen el trabajo, desplazando a la masa laboral humana. En definitiva, esto no puede ser tenido como una causa justa para un despido objetivo procedente, por cuanto lo contrario implicaría favorecer la subestimación y minimización del Derecho al Trabajo.

La correcta interpretación del artículo 52 c) ET, no puede llevar a confundir la mera conveniencia empresarial de reducir costes, con la necesidad de superar desajustes entre la fuerza laboral y la oferta. No se debe olvidar que la finalidad de este precepto legal es la de contribuir a ayudar a la empresa que atraviesa dificultades o bien en el ámbito económico global, o bien en un área determinada de la empresa; y no la de configurar un sistema de incremento de los beneficios en aquellas empresas que, no atravesando complicación alguna, pretenden acogerse al mismo ante cualquier eventualidad o circunstancia que se produce en su proceso técnico, productivo y de organización, trasladando al trabajador los riesgos de la actividad empresarial y haciendo recaer sobre el mismo cualquier incidencia del mercado. De escasa relevancia y nula incidencia en su normal funcionamiento, o servir de subterfugio para evitar llevar a cabo una negociación con los trabajadores por las que se les establezcan y reconozcan una serie de derechos y garantías laborales, como implicaría la masiva sustitución de trabajadores por automatismos robóticos.

En el supuesto que se analiza no se ha producido un problema o desajuste entre la demanda existente en el mercado y la fuerza laboral existente en la empresa, sino que ha sido la propia empresa, que no tenía problemas previos, la que ha introducido un elemento que ha creado dicho desajuste, al adjudicar a un bot el trabajo que antes desempeñaban humanos. La sentencia determina que no había una carga de trabajo inasumible que justificara la introducción de un

\footnotetext{
${ }^{27}$ STSJ de País Vasco, de 1 de octubre de 1996.
} 
elemento robótico que se encargara de dicho excedente de trabajo. Asimismo, no se ha probado que el descenso de trabajo haya implicado la conveniencia, por ser más económico, de tener un bot trabajando 24 horas al día, frente a un trabajador cuyos derechos son no trabajar más de 40 horas semanales de jornada ordinaria.

La razonabilidad de la medida no puede encontrarse en la mera conveniencia económica de introducir la inteligencia artificial que trabaje 392 horas al mes, frente a una persona que, por derechos sociales alcanzados, no debería trabajar más de 160 horas al mes; ni por la mejor conveniencia económica de pagar 12.900 euros anuales por una licencia, frente a los 28.412,44 euros anuales de un trabajador, suponiendo un ahorro en salarios y sobre todo en cotizaciones a la Seguridad Social.

En definitiva, la automatización - como causa técnica del despido objetivo - implica una oposición entre los Derechos Sociales alcanzados por los trabajadores (salario mínimo, jornada laboral, limitación de horas extraordinarias), que se vislumbran como obstáculo u óbice para alcanzar un rendimiento empresarial más óptimo, frente a la posibilidad de que un instrumento de producción pueda efectuar ese mismo trabajo sin límite de horas, sin salario ni cotizaciones sociales. Por consiguiente, la automatización mediante bot o robots, con la única excusa de reducir costes para aumentar la competitividad, viene a significar lo mismo que reducir el Derecho al Trabajo para aumentar la libertad de empresa.

Por último, se han dado voces al indicar que "el gran objetivo de poner diques de contención al irrefrenable cambio tecnológico pasa por la plena concienciación de todos los agentes sociales, económicos y políticos sobre los devastadores efectos del "tsunami tecnológico" que se atisba en el horizonte. Esta sentencia, desde luego, nos pone en la senda de este trascendental debate" 28 .

\section{CONCLUSIONES}

Como se ha podido deducir del estudio, el juzgador en cuestión valora la razonabilidad, proporcionalidad y justificación de la medida y, con fundamento en esa ponderación, califica el despido objetivo de improcedente, otorgando a la trabajadora el añadir la diferencia indemnizatoria a la cantidad ya cobrada por el despido objetivo. Tras la reforma laboral de 2012 del ET, a través de la Ley 3/2012, de 6 de julio, de medidas urgentes para la reforma del mercado laboral (Ley $3 / 2012)^{29}$, se han ampliado las causas técnicas, organizativas, productivas y económicas que justifican el despido procedente. Independientemente de que la ley sea más

\footnotetext{
${ }^{28}$ MERCADER UGUINA, J., "Despido de una administrativa cuyo trabajo ha sido sustituido por un Robot: ¿es posible poner Puertas al Campo?”, El Foro de Labos, https://forodelabos.blogspot.com/2019/10/despido-de-unaadministrativa-cuyo.html

${ }^{29}$ BOE núm. 162, de 7 de julio de 2012.
} 
flexible no exime al empresario de la obligación de comprobar que realmente, y de manera efectiva, se encuentra en tal dificultad como para extinguir el contrato laboral.

Por consiguiente, la cuestión está en dilucidar si la automatización de tareas en las empresas puede entrar en el cauce de estas causas objetivas, así como para que un despido sea procedente. Hay que destacar que la Ley 3/2012 dispone que se puede extinguir el contrato cuando existan alguna de las causas enumeradas en el artículo 51.1 del ET, en materia de despido colectivo; aunque no se cumplan el volumen de trabajadores previstos para considerarlo como tal, pudiendo acogerse a causas económicas, técnicas, organizativas o de producción. Por consecuencia, el empresario podrá acogerse a causas técnicas "cuando se introduzcan cambios, entre otros, en los medios o instrumentos de producción". Para que existan causas económicas hay que constatar las pérdidas económicas actuales o previstas o cuando exista una disminución persistente o prevista de los ingresos o ventas respecto al periodo de referencia que establece la ley.

El concepto y la finalidad, por tanto, de la extinción de contratos de trabajo por causas objetivas con base en razones económicas, técnicas, organizativas o de producción no se ha modificado. Por lo que sigue estando configurado, a pesar de las reformas sufridas del artículo 52 del ET, como un mecanismo legal para la extinción de contratos de trabajo a menor coste del ordinario; cuando en la empresa concurren circunstancias de esa naturaleza y como instrumento para intentar mantener la actividad empresarial y conservar, de esa forma, los demás puestos de trabajo no afectados por tan drástica medida, pero no como ardid para reformar la estructura laboral de la empresa o evitar acudir a otros mecanismos que le generarían, de igual manera, una indemnización mayor.

Como se ha señalado en el estudio, la empresa en cuestión avala las causas técnicas para justificar el despido objetivo de la trabajadora de la empresa, entregando como prueba un informe sobre las perspectivas turísticas en enero de 2019 en el que sin ningún dato objetivo se señala que se prevé un empeoramiento de las ventas. Este argumento para la sentencia es que "supera lo puramente técnico, y que supera incluso la libertad de empresa", por lo que pone en peligro la estabilidad del empleo.

Aunque se reconozca que la innovación tecnológica puede motivar la reducción del trabajo manual, en este preciso caso de la empresa hotelera, no se trataría de una reducción de mano de obra; sino de una completa sustitución del trabajo de una persona por un software, en el que "sería como considerar al trabajador un instrumento", por lo que implica "favorecer con el pretexto de la competitividad la subestimación y minimización del Derecho al Trabajo”.

Huelga recordar que del artículo 38 de la Constitución Española $(\mathrm{CE})^{30}$ reconoce el derecho a la "Libertad de empresa", pero este no puede entrar en conflicto con los derechos sociales y el propio Derecho al Trabajo, el cual debe ser garantizado. Por lo que resulta inadmisible que la

\footnotetext{
${ }^{30}$ BOE núm. 311, de 29 de diciembre de 1978.
} 
"mejora de la competitividad sea un elemento único para justificar un despido mediante la introducción de bots que automatizan el trabajo desde el punto de considerar como innecesario el trabajo humano". En este sentido, para extraer del ordenamiento jurídico la hipótesis de la existencia de una prohibición de contratación limitada de la libertad de empresa ésta debe ser expresa y directa; y el Estatuto de los Trabajadores no lo establece.

En definitiva, dando respuesta a la pregunta del título de este estudio: "El despido de los trabajadores por la automatización de sus puestos de trabajo ¿es posible?". La respuesta para ello es que a falta de una regulación expresa para la implantación de la Industria 4.0, desde el Derecho del Trabajo, será el órgano judicial, o en su caso los convenios colectivos a través de los interlocutores sociales, los que pongan cause a esta realidad que inevitablemente hay que vivirla, dado que las tecnologías han llegado para quedarse. Por lo que la sentencia en cuestión aclara que, aunque la legislación española desde la reforma laboral es más flexible a la hora de justificar un despido por causas objetivas, resulta necesario, por tanto, recurrir a una causa excepcional; y afirma que la automatización de tareas que hasta ahora desarrollaba una persona, no puede ser considerada como tal. Por consiguiente, la respuesta a la pregunta es negativa.

Hay que destacar que la sentencia que se ha hecho alusión en este estudio ha tenido sus defensores y detractores. Los primeros, señalan, por un lado, que es una "sentencia bien trabajada y argumentada, cuyos avatares jurídicos (es decir recurso) será conveniente seguir. En cualquier caso, el impacto del cambio tecnológico es real en todas las facetas de la vida laboral, y es tarea del mundo empresarial y de las organizaciones sindicales y representaciones del personal en la empresa pactar los términos de las transformaciones y adaptaciones para que el o los cambios resulten positivos para las personas afectadas. ¿Ello quiere decir que seria conveniente que no hubiera casos como el que ha conocido, y resuelto, la sentencia analizada? Pues, con toda sinceridad, sín ${ }^{\prime 31}$.

Por otro, "no es dable que, en casos como el presente, en el que la automatización viene a sustituir a los trabajadores en sus tareas, hasta desplazar a la masa laboral del mercado, por la mera competitividad de la empresa, pueda esta acogerse a una forma privilegiada de despido en la que se abona al trabajador una indemnización inferior a la ordinaria" ${ }^{32}$. Al igual se señala que si "se admitiese que aumentar la productividad es un motivo válido para despedir a un trabajador y sustituirlo por una máquina, podríamos llegar a destruir el 35\% de puestos de

\footnotetext{
${ }^{31}$ ROJO TORRECILLA, E., "Sustitución de una trabajadora por un bot de gestión. Necesidad de justificar la causa de la decisión empresarial", http://www.eduardorojotorrecilla.es/2019/10/sustitucion-de-una-trabajadora-porun.html

${ }^{32}$ LARAÑA COBO, M., “Sustituir a un trabajador por un robot es despido improcedente?”, The Techno Lawgist, https://www.thetechnolawgist.com/2019/10/14/sustituir-un-trabajador-por-un-robot-despido-improcedente/
} 
trabajo - teniendo en cuenta los datos del dossier de BBVA Research, ¿Cuán vulnerable es el empleo en España a la revolución digital? - que se prevén para los próximos años"33.

Los segundos, establecen, por una parte, que "no se puede avizorar, en definitiva, si esta sentencia, como todo esfuerzo inútil, conduce a la melancolía de la búsqueda inconsecuente de un principio de legitimación, o si, por el contrario, verdaderamente ha abierto una brecha consolidada en el muro de silencio normativo con respecto a dicha legitimación. Porque no se tiene claro, en definitiva, si se pueden emplear estas causas -organizativas, técnicas, productivas- sin necesidad de acudir a la tradicional fuente de legitimación (...) Lo cual nos sitúa en otro escenario: ¿es razonable, valga la redundancia, que sí sea necesario implementar el juicio de razonabilidad para las causas productivas -argumento perfectamente predicable también de las causas técnicas y organizativas- pero que no lo sea para las causas económicos? (...) si finalmente la resolución es impugnada en suplicación, qué tiene que decir al respecto el TSJ, que básicamente tiene dos opciones: continuar con esta línea 'Avant-garde', novedosa y modesta pero firmemente- disruptiva, o, por el contrario, retraerse al texto preciso de la norma sin acudir al de su espíritu y finalidad del que se embebía la misma causa en sus anteriores redacciones, para considerar que efectivamente la reforma laboral del 2012 le ha dado un vuelco definitivo a esta causa de extinción objetiva al desconectar su operatividad técnica de la supervivencia de la empresa que se encuentra en crisis" 34 .

Por otra, la "lectura de la fundamentación de la sentencia es muy sugerente y plantea interesantes y profundas controversias. Comparto el fallo de la sentencia (la improcedencia), pero discrepo (en una parte muy considerable) de la argumentación esgrimida"35. De igual manera, se afirma que si "ya el preacuerdo del Pacto de Toledo alcanzado en febrero del año 2019 deja abierta la posibilidad de que los robots puedan llegar a cotizar, señalándolos como entes de una realidad existente, ¿qué sentido tienen sentencias como la que es objeto de análisis, que penalizan la implementación de cambios tecnológicos en el sector empresarial?’36.

Finalmente, hay que destacar que la cuarta revolución industrial cuanta con dos caras. Por un lado, "la de las nuevas oportunidades de desarrollo para la sociedad en su conjunto". Por otro, "la de los riegos de todo tipo a los que nos hemos de enfrentar y que no son desconocidos en

\footnotetext{
${ }^{33}$ SÁNCHEZ MUÑOZ, E., “¿Es legal despedir a un trabajador por una máquina? Un Juzgado de lo Social canario falla en contra”, http://www.cielolaboral.com/wpcontent/uploads/2019/10/sanchez_munoz_noticias_cielo_n9_2019-2.pdf

${ }^{34}$ ARIAS DOMÍNGUEZ, Á., “¿Se considera procedente la extinción objetiva (por causa técnica) de un trabajador que ha sido sustituido por un robot?", Revista de Jurisprudencia Laboral, núm. 7, 2019, https://www.boe.es/publicaciones/anuarios_derecho/articulo.php?id=ANU-L-2019-00000000656

${ }^{35}$ BELTRAN DE HEREDIA RUIZ, I., “Automatización y despido objetivo”, Una mirada crítica a las relaciones laborales, https://ignasibeltran.com/2019/10/09/automatizacion-y-despido-objetivo-sjs-10-las-palmas-23-9-19/

36 ETXENAGUSIA IZQUIERDO, A., “_robots o trabajadores?”, https://www.barrilero.com/robots-otrabajadores/?lang=en
} 
buena parte de los casos"37. Riesgo como el que se acaba de estudiar con relación a los despidos por la automatización de los puestos de trabajo; en que hay que entender el riesgo como los "peligros que se analizar activamente en relación a posibilidades futuras. Solo alcanza un uso extendido en una sociedad orientada hacia el futuro" 38 .

Bajo este contexto, la experiencia ha revelado "cómo el poder tecnológico del empresario pone en peligro y moviliza numerosas libertades públicas, tales como el derecho a la intimidad, el secreto de las comunicaciones, el derecho a la propia imagen o la libertad informática. Y ese poder puede ser adicionalmente utilizado, de manera directa o indirecta, con fines discriminatorios. Este carácter pluriofensivo de los adelantos técnicos, particularmente manifiesto ante el ingente almacenamiento de datos que permite la reconstrucción de las señas e identidades más profundas de la profesionalidad y de la personalidad de los trabajadores, obliga a buscar el difícil punto de equilibrio entre el derecho del empresario a optimizar las posibilidades que las nuevas tecnologías ofrecen no sólo a la actividad económica sino a la gestión del personal, y el ejercicio por los trabajadores, en el seno de la relación laboral, de sus derechos de ciudadanía"39.

\section{BIBLIOGRAFÍA}

ARIAS DOMÍNGUEZ, Á., “¿Se considera procedente la extinción objetiva (por causa técnica) de un trabajador que ha sido sustituido por un robot?", Revista de Jurisprudencia $\begin{array}{lll}\text { Laboral, núm. } & \text { 2019, }\end{array}$ https://www.boe.es/publicaciones/anuarios_derecho/articulo.php?id=ANU-L-201900000000656

BELTRAN DE HEREDIA RUIZ, I., “Automatización y despido objetivo", Una mirada crítica a las relaciones laborales, https://ignasibeltran.com/2019/10/09/automatizacion-ydespido-objetivo-sjs-10-las-palmas-23-9-19/

CCOO INDUSTRIA, Industria 4.0. Una apuesta colectiva, CCOO, Madrid, 2015.

CCOO INDUSTRIA, La Digitalización y la Industria 4.0: Impacto industrial y laboral, CCOO, Madrid, 2017.

COM (2016) 356 final, Una Agenda Europea para la economía colaborativa.

\footnotetext{
${ }^{37}$ GARCÍA JIMÉNEZ, M., "Revolución Industrial 4.0, Sociedad cognitiva y relaciones laborales: retos para la negociación en clave de bienestar de los trabajadores", Revista de Trabajo y Seguridad Social. CEF, núm. Extraordinario, 2019, pág. 55.

${ }^{38}$ GIDDENS, A., Un mundo desbocado. Los efectos de la globalización en nuestras vidas, Taurus, Madrid, 2000, pág. 35.

${ }^{39}$ RODRÍGUEZ ESCANCIANO, S., Derechos laborales digitales: garantías e interrogantes, Thomson Reuter Aranzadi, Cizur Menor, 2019, pág. 17.
} 
DOMÉNECH, R., GARCÍA, J., MONTAÑEZ, M. y NEUT, A., “¿Cuán vulnerable es el empleo en España a la revolución digital?”, BBVA Research, Observatorio Económico, 19 de marzo de 2018.

ETXENAGUSIA IZQUIERDO, A., “irobots o trabajadores?”, https://www.barrilero.com/robots-o-trabajadores/?lang=en

GARCÍA JIMÉNEZ, M., "Revolución Industrial 4.0, Sociedad cognitiva y relaciones laborales: retos para la negociación en clave de bienestar de los trabajadores", Revista de Trabajo y Seguridad Social. CEF, núm. Extraordinario, 2019.

GIDDENS, A., Un mundo desbocado. Los efectos de la globalización en nuestras vidas, Taurus, Madrid, 2000.

LARAÑA COBO, M., “¿Sustituir a un trabajador por un robot es despido improcedente?”, The Techno Lawgist, https://www.thetechnolawgist.com/2019/10/14/sustituir-untrabajador-por-un-robot-despido-improcedente/

MERCADER UGUINA, J., El futuro del trabajo en la era de la digitalización y la robótica, Tirant lo Blanch, Valencia, 2017.

MERCADER UGUINA, J., "Despido de una administrativa cuyo trabajo ha sido sustituido por un Robot: ¿es posible poner Puertas al Campo?”, El Foro de Labos, https://forodelabos.blogspot.com/2019/10/despido-de-una-administrativa-cuyo.html

MCKINSEY \& COMPANY, Four fundamentals of workplace automation, McKinsey Quarterly, noviembre de 2015.

MINISTERIO DE INDUSTRIA, ENERGÍA Y TURISMO, Industria conectada 4.0: La transformación digital de la industria Española, Ministerio de Industria, Energía y Turismo, Madrid, 2015.

MORRON SALMERON, A., ¿Llegará la Cuarta Revolución Industrial a España?, CaixaBank Research, febrero, 2016.

ROCHA, F., La crisis económica y sus efectos sobre el empleo en España, Gaceta Sindical, CCOO, Madrid.

RODRÍGUEZ ESCANCIANO, S., Derechos laborales digitales: garantías e interrogantes, Thomson Reuter - Aranzadi, Cizur Menor, 2019.

ROJO TORRECILLA, E., "Sustitución de una trabajadora por un bot de gestión. Necesidad de justificar la causa de la decisión empresarial", http://www.eduardorojotorrecilla.es/2019/10/sustitucion-de-una-trabajadora-porun.html 
SÁNCHEZ MUÑOZ, E., “¿Es legal despedir a un trabajador por una máquina? Un Juzgado de lo Social canario falla en contra", http://www.cielolaboral.com/wpcontent/uploads/2019/10/sanchez_munoz_noticias_cielo_n9_2019-2.pdf

TORNABELL CARRIO, R., "Industria 4.0: ¿Qué impacto tiene en la producción y el empleo?”, La Revista del Foment, núm. 2146, 2016.

WORLD ECONOMIC FORUM, The Future of Jobs Employment, Skills and Workforce Strategy for the Fourth Industrial Revolution, World Economic Forum, Ginebra, 2016.

\section{ABREVIATURAS}

CCOO Comisiones Obreras

CE Constitución Española

EPA Encuesta de Población Activa

ET Real Decreto Legislativo 2/2015, de 23 de octubre, por el que se aprueba el texto refundido de la Ley del Estatuto de los Trabajadores

Ley 3/2012 Ley 3/2012, de 6 de julio, de medidas urgentes para la reforma del mercado laboral

RAE Real Academia Española

RPA Robotic Process Automation

STS Sentencia del Tribunal Supremo

STSJ Sentencia del Tribunal Superior de Justicia 
